Motrivivência Ano XXIV, No 38, P. 135-148 Jun./2012

http://dx.doi.org/10.5007/2175-8042.2012v24n38p135

\title{
PROGRAMAS SOCIAIS DE ESPORTE E LAZER NA ESCOLA E NA COMUNIDADE: as evidências de exclusão social e educacional na sociedade brasileira
}

Celi Zulke Taffarel ${ }^{1}$

\section{RESUMO}

O texto apresenta conteúdos referentes à contradição "exclusão x inclusão", considerando a realidade atual de franca decomposição do modelo capitalista e da destruição das forças produtivas, o que determina a possibilidade de acesso aos bens historicamente acumulados. O faz partindo da contradição entre trabalho e capital que se expressa na produção social e na apropriação privada dos bens culturais, entre os quais a própria educação e o esporte. Discute indicadores das avaliações educacionais e as reivindicações dos trabalhadores e, um programa de transição na perspectiva da alternativa de projeto histórico para além do capital.

Palavras-chave: Política pública; Programas sociais; Educação e Esporte.

EXCLUSÃO X INCLUSÃO: UMA FALSA POLÊMICA - OS CONCEITOS

A polêmica em torno de políticas sociais de "exclusão e inclusão" é uma falsa polêmica quando desconsidera fatores da economia política que, em última instância, determinam, em uma sociedade dividida em classes sociais, qual é a classe social que detém os meios de produção e, portanto, se apropria privadamente dos bens produzidos socialmente e dos lucros, das riquezas geradas pelo trabalho humano.

Exclusão e inclusão social não podem ser analisadas em separado porque constituem um par dialético com pólos em contradições. Inclusão social em uma sociedade de classes representa a aparência de uma realidade que, para ser explicada, exige a consideração das leis gerais que regem o

1 Professora Dra. Titular FACED/UFBA. Contato: taffarel@ufba.br 
modelo do capital organizar a produção e reprodução dos bens, as contradições na organização do poder no Estado capitalista e, fundamentalmente, as expressões da luta de classes, ou seja, o enfrentamento entre interesses antagônicos e altamente conflitantes que também determinam a vida na sociedade.

Estes três elementos - leis gerais do capital, organização do Estado burguês e a luta de classes -, possibilitam demonstrar que é próprio do modo do capital organizar a produção e reprodução da vida, a destruição das forças produtivas.

"Forças produtivas" é uma categoria teórica composta pelo trabalho humano, à natureza, que é transformada e transforma o ser humano, no processo de produção de bens materiais e imateriais para a manutenção da vida. Bens estes que são produzidos para fins de uso e de troca em relações sociais de produção. Estas relações de produção e troca, baseadas na propriedade privada dos meios de produção e, da apropriação do trabalho humano através do assalariamento, determinam e exclusão, o não acesso, o que se caracteriza como uma tendência do capitalismo em franca degeneração e decomposição, o capitalismo rentista, parasitário, que na atualidade encontra-se em sua fase mais avançada, a imperialista (LENIN, 2007). Portanto, o primeiro conceito a esclarecer é sobre o complexo econômico em que vivemos e o que é exclusão e inclusão neste modo de produção da vida.

Pertencer ou não, estar incluído ou não, estar excluído ou não, ter acesso ou não, na escola, na universidade nas atividades culturais esportivas, sejam quais forem elas, em uma sociedade organizada em classes sociais requer sabermos a que classe social estamos nos referindo. Sabermos de que ordem são os obstáculos criados para impedir o acesso, a inclusão. Estamos nos referindo aos obstáculos criados pelos detentores dos meios de produção que impedem aos que vendem sua força de trabalho para poderem sobreviver, o acesso pleno aos bens que são socialmente produzidos. Estamos falando dos $20 \%$ da sociedade que detém mais de $70 \%$ dos bens, ou dos demais $80 \%$ que detém menos de $30 \%$ dos bens e dependem, para sobreviver, da ação do Estado na implementação de políticas públicas que garantam a repartição das riquezas geradas pelo trabalho da classe trabalhadora?

Exclusão e inclusão são, conforme nos demonstra Luiz Carlos de Freitas (2003), um par dialético cujo conteúdo só é revelado se a abordagem for feita em conjunto e não isoladamente por um dos pólos "excluir-incluir". Esta contradição não se resolve por um dos pólos, ou seja, vamos incluir e está resolvido o problema. A solução da exclusão ou inclusão não se dá intrinsicamente por um destes pólos, mas sim, pela resolução da contradição fundamental, a contradição entre trabalho e capital. Entre produção social dos bens e apropriação privada dos bens.

O modo econômico atual, onde o trabalho humano está subsumido ao capital, que se caracteriza pela super exploração da mais-valia, pela propriedade privada dos meios de produção, pela produção coletiva e apropriação privada dos bens materiais e imateriais, pela violenta destruição do meio ambiente, está em franca degeneração (A VERDADE N. 73, 2012, p. 05-22).

O imperialismo, segundo Lênin (2007), surgiu como desenvolvimento e seqüência direta das propriedades essenciais 
do capitalismo em geral. O Imperialismo é: a substituição da livre concorrência pelos monopólios e se caracteriza pela: 1) concentração da produção e do capital atingindo um grau de desenvolvimento tão elevado que origina os monopólios cujo papel é decisivo na vida humana; 2 . fusão do capital bancário e do capital industrial, e criação, com base nesse "capital financeiro" de uma oligarquia financeira; 3) diferentemente da exportação de mercadorias, a exportação de capitais assume uma importância muito particular; 4) formação de uniões internacionais monopolistas de capitalistas que partilham o mundo entre sí; 5) termo de partilha territorial do globo entre as maiores potencias do mundo". Ainda segundo Lênin (2007, p. 17) sem se compreender a origem econômica deste fenômeno, sem medir a sua importância política e social, é impossível avançar um passo que seja na realização das tarefas práticas do movimento comunista e da revolução social do futuro.

Portanto, no marco do imperialismo, cuja base econômica é a dominação de uma nação sobre a outra, vivem enormes contingentes humanos condenados a morte, uma morte cruel, porque muitas vezes morre-se em guerras, mas, também, morre-se de fome, por doenças, pelas drogas e, por não suportar as intempéries, como foi o que aconteceu em Nova Orleans, Estados Unidos, quando da passagem do furacão Katrina, onde se romperam diques de represas provocando mortes desnecessárias. Contraditoriamente, mortes conseqüentes do próprio modo de organizar a vida.

Esses contingentes humanos, localizados principalmente em regiões que já foram altamente exploradas pelos imperialistas como o Haiti, a África e a América Latina, reagem, e a reação é a organização em torno de necessidades e reivindicações: convertem-se nos movimentos de luta social. Além das intempéries enfrentam o braço armado do Estado capitalista e combatem o imperialismo exigindo a nacionalização das riquezas, lutando contra a privatização do patrimônio público, contra o repasse de verbas públicas para o setor privado, defendendo os serviços públicos. São homens e mulheres negros, brancos, amarelos, indígenas, populações desapropriadas, velhos, jovens e até crianças que se organizam, lutam, resistem, reagem a um modo econômico altamente destrutivo. São os que possuem somente a sua própria força de trabalho para vender e manter a vida (MARX, 1980), os que pertencem à classe trabalhadora.

Da luta e do confronto de classes, originarias, portanto, da divisão social do trabalho é onde vamos localizar a origem dos movimentos de luta. Não nos iludimos com os chamados "Novos Movimentos Sociais" (NMS) que negam sua origem de classe porque mesmo negando tal origem, em última instância, vamos localizar esta categoria fundamental determinando as condições da existência - a luta de classes.

Ao analisar as classes sociais no capitalismo destacamos a necessidade de reconhecer, sobretudo, os inimigos e os aliados potenciais da classe operária e, ainda, a necessidade da análise das determinações objetivas da luta de classes que são freqüentemente negligenciadas. Isto porque classes sociais na teoria marxista são conjuntos de agentes sociais determinados, principalmente, mas não exclusivamente, por seu lugar no processo de produção, isto é, na esfera econômica. Agem aí, também, os fatores políticos e ideológicos, que designam os lugares objetivos ocupados pelos 
agentes na divisão social do trabalho. Portanto, podemos reconhecer os movimentos sociais de luta pelo lugar que ocupam na luta de classes decorrente da divisão social do trabalho.

Beer (2006) nos apresenta elementos para conhecer as lutas sociais na antiguidade até a época contemporânea. A luta do movimento socialista no mundo demonstra a resistência dos povos contra a destruição da lógica do capital. Engels (S/D) em sua obra "Do socialismo utópico ao socialismo científico" também localiza a luta histórica dos trabalhadores organizados em organismos internacionais ${ }^{2}$ para fazer frente às brutais condições de vida que o capitalismo emergente assegurava no inicio da revolução industrial. Outro exemplo é a histórica luta dos trabalhadores da cidade em união com os trabalhadores do campo, no Leste Europeu, que chegaram ao poder, derrubando o czarismo e o governo provisório de Kerensky em 7 de novembro de 1917 constituindo a União Soviética. Mais um exemplo é a resistência organizada, contra o imperialismo, a ofensiva da Revolução Cubana (1957- 1967); as lutas urbanas de massa contra regimes militares em toda a América Latina (1968-1976), a Revolução Sandinista e as ofensivas populares (19791998); as lutas rurais, as ligas camponesas, a luta no campo, a luta do Movimento dos Trabalhadores Rurais Sem Terra, dos Atingidos por Barragens, dos Extrativistas, dos Quilombolas, as resistências e as ofensivas mundiais como a luta dos povos contra o imperialismo no oriente médio, na Palestina, Irã, Iraque (TADDEI e SEOANE, 2001). As lutas atuais em defesa dos organismos de classe e pela construção de pólos de resistência contra o imperialismo. Dentro destas lutas vamos localizar reivindicações transitórias e históricas, entre elas, o acesso aos bens culturais materiais e imateriais, como a educação e o esporte.

Nessas lutas aprendemos lições completamente contrárias às lições dos dominantes, dos imperialistas e seus intermediários, os bancos, como o BM - Banco Mundial, o FMI - Fundo Monetário Internacional, a OMC - Organização Mundial do Comércio que, por anos e anos, orientam as políticas educacionais, agrárias e de esporte no Brasil e vêm destruindo direitos, culturas e retirando da classe trabalhadora as condições de acessarem bens produzidos socialmente (DE TOMMASI; WARDE; HADDAD; 1996).

Essas resistências estão sendo estudadas a partir da categoria analítica imperialismo, a estrutura do poder mundial, o

2 A Primeira Internacional (25.09.1864) foi fundada em Genebra, com a atuação militante de Marx e Engels. São os setores mais avançados do movimento operário que dão uma expressão orgânica e ativa ao programa internacionalista da revolução proletária. A Segunda Internacional (1889), da qual Engels foi um dos fundadores, votou o dia $1^{\circ}$ de maio comemorativo do Dia Internacional do Trabalho. Termina por apoiar os governos dos países imperialistas da Europa votando os créditos de guerra e conseqüentemente apoiando a matança dos trabalhadores de cada país por seus irmãos de classe. A Terceira Internacional (1919), formada pelo Partido Bolchevique após a Revolução Russa, posteriormente à vitória de Stalin e de sua política de "Socialismo em um só país", se transforma em instrumento de política externa da URSS. Rompendo com a III Internacional em 1938 por entender que os Partidos haviam se tornado organizações contra-revolucionárias que trabalhavam unicamente para defender os interesses da casta burocrática de Moscou e não mais os do proletariado mundial, Leon Trotsky funda a Quarta Internacional. Diversas organizações aderiram a Quarta e passaram a ter como eixos político-programáticos o internacionalismo, o Programa de Transição elaborado por Trótsky e a Teoria da Revolução Permanente, de que a revolução proletária é mundial e somente assim poderá ser vitoriosa. 
papel exercido pelos organismos financeiros internacionais, as características da relação capital-trabalho no mundo contemporâneo e as atribuições dos Estados nacionais no processo de transnacionalização do capital e, da acentuação da destruição das forças produtivas. Muitas são as experiência, à exemplo do zapatismo no México, os protestos de Seattle, de Praga, as Marchas Mundiais dos povos, a resistências das muIheres da Via Campesina, a luta exemplar da Comuna de Paris à Comuna de Oaxaca no México, à luta dos trabalhadores no continente europeu, contra os planos de austeridade impostos pelo Banco Europeu, o FMI, o Banco Mundial, que visam assegurar a pilhagem no mundo.

Estas lutas refletem a luta da classe trabalhadora, nacional e internacional, contra o capital e sua forma de organizar a vida. Classes são antagônicas porque uma se apropria do trabalho da outra em função do lugar distinto que ocupam na estrutura econômica de um modo de produção que está determinado, fundamentalmente, pela forma específica em que se relaciona com os meios de produção. ${ }^{3}$ A luta de classes diz respeito aos interesses antagônicos e podemos constatá-la na construção histórica da humanidade e localização na divisão social do trabalho. Esse movimento, que constitui a práxis da humanidade, se dá de maneira utilitária quando se mantém o modo de vida e de maneira revolucionária quando o modo de vida é revolucionado (KOSIK,
1976). É, portanto, na práxis da humanidade que se desenvolvem as leis e categorias do pensamento e esse acúmulo histórico permite não somente constatar, generalizar e sistematizar, mas, criticar e transformar o concreto aparente em real concreto. É na práxis revolucionária que vamos localizar os elementos de superação do modo do capital organizar a vida. Isto significa a construção de uma outra subjetividade humana, decorrente da internalização de outras relações sociais de produção da vida, com outra objetivação do ser humano transformando o meio e se transformando a si mesmo.

\section{A SITUAÇÃO DA EDUCAÇÃO E DO ES- PORTE NO BRASIL}

Os séculos de colonialismo e atualmente de imperialismo devastaram o Brasil que pode ser caracterizado como um pais neocolonial considerado o seu modelo econômico agro-exportador. Isto pode ser constatado nos fatos que destacamos para exemplificar o desmonte da soberania da nação brasileira. Um diz respeito ao Orçamento Geral da União e a sangria dos recursos públicos e, outro, a situação da educação e do esporte no Brasil.

O projeto de Lei Orçamentária (LOA) para 2012, aprovado pelo Congresso Nacional mostra a transferência para os bancos de quase metade dos recursos da união (amortizações, juros, encargos financeiros e refinanciamento (troca de títulos),

3 Podemos localizar atualmente uma série de Movimentos relacionados as questões de genero, raça, étnia. Movimentos ecológicos, Movimentos religiosos, Movimentos de Organizações não Gpovernamentais em geral. Estes movimentos reivinicam ações repartórias e ações afirmativas que significa reivindicar do Estados politicas públicas focais, assistenciais, de acordo com questões de sexo, cor, raça, problema social, entre outros. Siqueira (2006) trata destes movimentos como Novos Movimentos Sociais e discute em sua tese de doutorado a questão da luta por cidadania no marco do capital e a luta pela emancipação humana que significa superar o modo do capital organizar a vida. 
ou seja, para os serviços da dívida pública serão destinados 47,19\% do Orçamento Geral da União. Em 2011 foram 45,05\% e em 2010 foram 44,93\% do total do Orçamento, segundo o sitio da Auditoria Cidadã da Divida.
Por outro lado, o montante previsto para Educação é de 3,18\%, Esporte 0,12, Cultura 0,09\%, Ciência e Tecnologia $0,43 \%$, o que representa menos do que vem sendo aplicado em média nos países da América Latina.

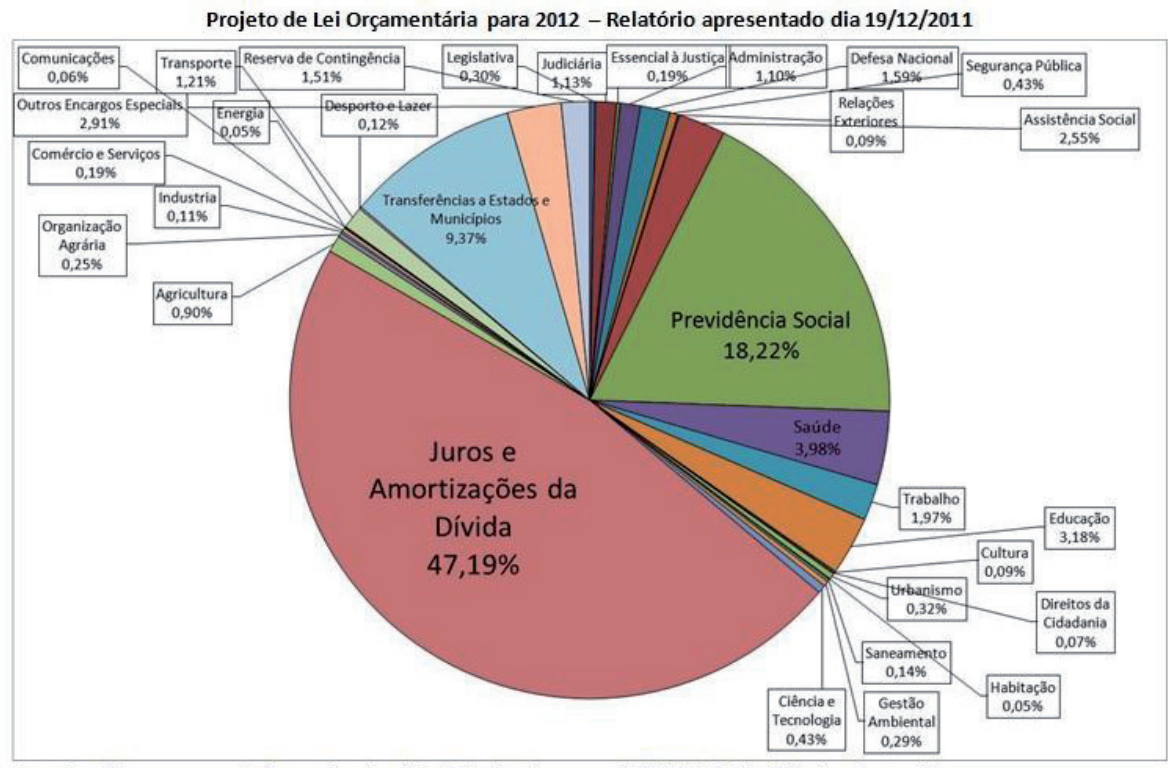

Fonte: $h$ ttp://www.camara.gov.br/internet/comissao/index/mista/orca/orcamento/or2012/rel final/vol4/02 desp funcao.pdf . http://www.camara.gov.br/internet/comissao/index/mista/orca/orcamento/or2012/rel final/vol4/12 desp paoe orgao.pdf, pág 84 .

A situação da Educação e esporte no Brasil pode ser verificada pelas avaliações e diagnósticos que vem sendo realizados. Para exemplificar destacamos os resultados do PISA - Programa Internacional de Avaliação Comparada -, cuja finalidade é produzir indicadores sobre a efetividade dos sistemas educacionais, avaliando o desempenho de alunos na faixa dos 15 anos, idade em que se pressupõe o término da escolaridade básica obrigatória na maioria dos países. Esse programa é desenvolvido e coordenado internacionalmente pela Organização para Cooperação e Desenvolvimento Econômico
(OCDE), havendo em cada país participante uma coordenação nacional. No Brasil, o PISA é coordenado pelo INEP - Instituto Nacional de Estudos e Pesquisas Educacionais "Anísio Teixeira". Os dados do PISA demonstram que no Brasil as crianças ingressam no ensino básico e quando chegam nas séries finais não estão plenamente letrados nas áreas de leitura, matemática e ciência. Ou seja, o país está entre os últimos no que diz respeito ao letramento dos jovens o que vem se confirmando em outras pesquisas. Isto significa que as crianças e jovens além de não ter acesso à educação 
quando o tem não são devidamente preparados para constatar, explicar e agir critica e criativamente no mundo.

O Letramento é avaliado em três dimensões: No campo da leitura avalia: 1 ). A forma do material de leitura. 2). O tipo de tarefa de leitura, o que corresponde às várias habilidades cognitivas próprias de um leitor efetivo. 3). O uso para o qual o texto foi construído. Por exemplo, um romance, uma carta pessoal ou uma biografia são escritos para uso "pessoal"; enquanto documentos oficiais ou pronunciamentos são para uso "público" e um manual ou relatório, para uso "operacional". No campo da Matemática é avaliado: 1). O conteúdo de Matemática, definido primeiramente em termos de conceitos matemáticos mais amplos (como estimativa, mudança e crescimento, espaço e forma, raciocínio lógico, incerteza e dependências e relações), e secundariamente em relação a ramos do currículo (como relações numéricas, álgebra e geometria). 2). O processo da Matemática, definido pelas competências matemáticas gerais. 3). As situações nas quais a Matemática é usada, variando de contextos particulares àqueles relacionados com questões científicas e públicas mais amplas. Quanto ao Letramento em Ciências é avaliado em três dimensões: 1). Conceitos científicos, necessários para compreender certos fenômenos do mundo natural e as mudanças decorrentes de atividades humanas. 2). Processos científicos, centrados na capacidade de adquirir, interpretar e agir com base em evidências. Cinco desses processos relacionam-se com: reconhecimento de questões científicas, identificação de evidências, elaboração de conclusões, comunicação dessas conclusões, demonstração da compreensão de conceitos científicos. 3). Situações científicas, selecionadas principalmente da vida cotidiana das pessoas. Assim como a Matemática, as ciências estão presentes na vida das pessoas em diferentes contextos, variando de situações pessoais ou particulares até questões públicas mais amplas, incluindo, algumas vezes, questões globais. O que os dados demonstram é que o Brasil não consegue efetivamente o letramento de seus jovens em leitura, matemática e ciências. Os que conseguem concluir o ensino básico - fundamental e médio, na grande maioria não, conseguem ingressar no ensino superior. Dos que ingressam no ensino superior a maioria paga para cursar a universidade privada.

O Panorama da Educação no Campo também nos apresenta dados catastróficos. Estes dados estão disponíveis em documentos do Ministério de Educação, INEP - Instituto Nacional de Estudos e Pesquisas Educacionais "Anísio Teixeira". Os diagnósticos preliminares têm apontado como principais questões: a insuficiência e a precariedade das instalações físicas da maioria das escolas; as dificuldades de acesso dos professores e estudantes às escolas, em razão da falta de um sistema adequado de transporte escolar; a falta de professores habilitados e efetivados, o que provoca constante rotatividade; a falta de conhecimento especializado sobre políticas de educação básica para o campo, com currículos inadequados que privilegiam uma visão urbana de educação e desenvolvimento; a ausência de assistência pedagógica e supervisão escolar nas escolas do campo; o predomínio de classes multisseriadas com educação de baixa qualidade; a falta de atualização das propostas pedagógicas das escolas do campo; baixo desempenho escolar dos estudantes e elevadas taxas 
de distorção idade-série; baixos salários, carreiras desestruturadas e sobrecarga de trabalho dos professores, quando comparados com os que atuam na zona urbana; a necessidade de reavaliação das políticas de nucleação das escolas; a implementação de calendário escolar adequado às necessidades do campo, que se adapte à característica flutuante das populações do campo, em função dos períodos de safra e da migração das famílias em busca de oportunidades de trabalho, entre outros.

Esta catástrofe social no Brasil vem sendo acompanhada pelo Banco Mundial que vem assumindo, desde a década de 80, o papel de monitorar processos de ajustes estruturais nos países dominados, principalmente os ajustes/adequações na "área social", dentre eles o do aparelho escolar. Ajustes que resultam de processos objetivos e expressão de interesses do imperialismo, porém, também de setores da classe dominante local. É importante ver como as propostas da burguesia industrial através da Confederação Nacional da Indústria coincidem com as propostas do imperialismo implementadas no Brasil sob a orientação do Banco Mundial. O discurso do Banco tem caráter humanitário corresponde às noções ideológicas de "justiça social" das classes dominadas dos países dominados, assumindo o combate à "pobreza", noção ideológica central no discurso de várias instituições dos Aparelhos de Estado: as diversas igrejas, OSCIP - Organizações da Sociedade Civil (Lei 9.790 de 23/03/1999) lei do Terceiro Setor que permite as ONGs - Organizações Não Governamentais, interferirem em áreas típicas do setor público, transferindo recursos públicos para o setor privado -, organizações políticas revisionistas, reformistas, populistas, etc. Esta atuação vai na direção de monitorar o ajuste estrutural dos países dominados de acordo com o rearranjo da economia mundial, abrir espaço para a valorização do capital, elaborar políticas de contenção da luta de classe acirrada com a implementação destes ajustes e planos de austeridade. Figueiredo (2011, p. 93-111) demonstra como os organismos internacionais subordinam planos educacionais aos seus ditames. A adoção da política de cotas é um exemplo.

$\mathrm{Na}$ educação os principais objetivos do Banco Mundial são: Ampliar a oferta do ensino fundamental público para manter sob controle as pressões sociais das classes dominadas, a população pobre, e para minar a resistência e a luta de classes das classes dominadas, e para isso é necessário adequar a escola no ensino fundamental a fim de trabalhar sob os critérios da produção capitalista (critérios de produção fabril): controle da produtividade; controle e avaliação de resultados; economia de custos; produção da mercadoria - no caso, educação - ao mais baixo custo possível, buscando formas, por exemplo, como a educação à distância, inclusive na formação de professores, portanto, com baixo nível de qualidade. A função aqui é conter a luta de classes. No geral é preparar a população "pobre" para ingressar, incluir, na economia "tradicional": trabalho por conta própria, trabalho informal, trabalho precarizado, trabalho na produção de mercadorias tradicionais, organização familiar do trabalho, entre outros. Essa característica também se observa no nível superior, vide cursos e pesquisas em arranjos produtivos locais, economia solidária, entre outras.

Iniciativas vêm sendo tomadas, principalmente por setores organizados para enfrentar esta situação. Vale destacar 
a socialização das iniciativas que vêm sendo conduzidas pelas Escolas Famílias Agrícolas e Casas Familiares Rural (CEFFAs), Movimento dos Trabalhadores Rurais Sem Terra (MST), Movimento de Educação de Base (MEB), Confederação Nacional dos Trabalhadores na Agricultura (Contag), entre outros, certamente deverão ser consideradas no estabelecimento de ações para a superação dos problemas relativos à educação no campo. Estas experiências constituem a base para a construção de uma política de educação do campo.

O que nos cabe perguntar é se as iniciativas do Estado brasileiro, conforme está configurado atualmente, após a Reforma do Estado (Plano Bresser Pereira, Novembro de 1995) e a adoção do Plano Econômico para Acelerar o Crescimento (PAC - 22 de Janeiro de 2007), a adoção do Plano de Desenvolvimento Educacional (PDE) terão condições de responder aos desafios colocados pela educação da cidade e do campo?

As analises empreendidas por Saviani (2009) acerca do PDE e a qualidade da educação básica questionam as bases de sustentação do PDE. A infraestrutura de sustentação do PDE são dois pilares o técnico e o financeiro. O ponto de vista técnico apóia-se em dados estatísticos referentes ao funcionamento das redes escolares e em instrumentos de avaliação constituída de indicadores do aproveitamento dos estudantes expressos nas provas aplicadas regularmente pelo INEP. Com isto é monitorada a implementação do PDE, definidas e redefinidas metas, orientadas e reorientadas as ações programadas e avaliado os resultados, etapa por etapa da operação do Plano até 2022. A outra base do PDE é do ponto de vista financeiro constituído de recursos advindos do FUNDEB que visa atender prioritariamente os mil municípios com os mais baixos níveis de qualidade aferidos pelo IDEB.

Após demonstrar criticamente o fracasso de medidas adotadas na educação, Saviani (2009, p. 31-41) destaca que não é insuficiente esta base e aponta um terceiro pilar para que o PDE obtenha êxito. Para ser posto em operação o PDE vai depender de recursos humanos, entre os quais avulta a questão dos professores que exigem dois requisitos fundamentais a serem preenchidos: as condições de trabalho e salários e a formação.

Criamos ilusões, falsidades, quando imaginamos poder incluir manejando o poder do Estado burguês, ou o processo de trabalho pedagógico que é uma variável intra-escola cuja determinação está para além da escola. Mais ainda, quando levantamos a falsa idéia de que "a Educação pode incluir alguém no sistema", sem compreender que as mobilidades sociais são exceções criadas pelo próprio sistema para manter sua hegemonia. Sejamos realistas, não existe possibilidade de inclusão, em um sistema cuja base fundamental é a exploração, explotação, a destruição.

Pablo Gentili (2001, p. 28) afirma que existem novas e não tão novas formais de exclusão social e educativas vividas hoje na América Latina, região marcada pela barbárie e a negação dos mais elementares direitos humanos a milhares de indivíduos. Estas formas de exclusão são a supressão completa de comunidades, os mecanismos de confinamento ou reclusão e a segregação inclusiva ou exclusão includente.

Os dados de inclusão no sistema de ensino, por exemplo, são meros artifícios quando inseridos no sistema mundial de educação. Os 39 milhões de analfabetos 
absolutos na América Latina são a marca do apartheid escolar. As crianças excluídas da escola e das atividades culturais em geral, em decorrência de guerras, de conflitos armados, pela exploração do trabalho infantil, pela exploração sexual, pelo desemprego dos pais são cada vez mais alarmantes. Quanto mais pobres as nações, mais ao sul, mais analfabetos, mais empobrecidos, mais endividadas, mais distantes estão do acesso aos bens culturais que garantem vida digna. Além disto, temos que reconhecer as novas formas de exclusão, via organização e trato com o conhecimento, avaliação-objetivos, organização do tempo pedagógico, financiamento da educação. É impossível deixar de reconhecer as contradições existentes entre a macroeconomia e as possibilidades de atendimento das reivindicações dos trabalhadores. O exemplo está sendo dado, por um governo que foi eleito por, aproximadamente, 52 milhões de eleitores para romper com a política liberal e o que estamos presenciando é o atendimento dos acordos internacionais com banqueiros imperialistas em detrimento das reivindicações dos trabalhadores.

Quando nos reportamos à situação do esporte no Brasil, enquanto patrimônio cultural da humanidade, socialmente produzido, historicamente apropriado, vamos verificar segundo dados do IBGE que faltam orçamentos, planos, programas, projetos, infraestrutura, pessoal nas prefeituras para assegurar a universalização e democratização de tais práticas corporais. A Educação Física está desaparecendo das escolas e as iniciativas governamentais de Programas Esportivos não atingem 20\% dos municípios brasileiros.

No que diz respeito ao Plano de Desenvolvimento do Esporte, constatamos que os Governos de Luiz Inácio Lula da Silva e Dilma Rousseff enfocaram a meta de tornar o Brasil um pais olímpico até 2022, desenvolvendo principalmente a infra-estrutura para a realização de mega eventos, mega espetáculos esportivos, trazendo para o Brasil os Jogos Pan-americanos, Campeonatos Mundiais como a Copa das Confederações, a Copa Mundial de Futebol em 2014 e as Olimpíadas em 2016. Os pilares do Plano esportivo são: o financiamento público maciço em obras de infraestrutura nas cidades sedes dos jogos, o marco regulatório que favorece os negócios em torno dos produtos esportivos e, a interferência do Estado via Ministério do Esporte em fomento, prioritário, ao esporte competitivo de alto rendimento. Os obstáculos a universalização e democratização do esporte estão determinadas neste momento por estes três pilares.

Pelos relatos expostos podemos concluir que não basta a discussão da exclusão $x$ inclusão. Temos que nos perguntar sobre a estrutura do Estado capitalista. Temos que nos perguntar sobre a escola capitalista.

A critica radical a escola que sociabiliza para o mundo do trabalho capitalista é o ponto de partida. Esta escola que ensina relações sociais submissas aos trabalhadores que aceitarão mais facilmente a sociedade atual, e não farão nada para alterá-la. As crianças aprendem muito pouco na escola, para além da submissão e isto é um ganho para o capital. Continuar explorando trabaIhadores alienados que não conseguem se identificar com suas produções, com suas relações, consigo mesmo, instruindo os que mandam, é a função estratégico da escola capitalista. Escola que nega conhecimentos e não desenvolve as funções psicológicas superiores. Identificamos estas contradições na negação do conhecimento. Identificamos 
esta negação de conhecimentos na escola estudando o caso do conhecimento no campo da cultura corporal. Este conteúdo que deve ser criticamente ensinado, criativamente praticado, ludicamente exercitado está desaparecendo dos currículos escolares. As explicações sobre esta negação não reside só na boa vontade ou não do professor, mas, sim, na própria destruição das forças produtivas, na destruição dos serviços públicos, na destruição da escola pública. Trabalhadores cada vez mais escassos, para empregos mais escassos, facilmente substituídos por máquinas, não necessitam compreender o que significa a cultura corporal na história da humanidade. Os poucos que conseguirão trabalho poderão recorrer a outros meios para acessar tal bem cultural para consumo próprio, por exemplo, através do "personal trainer", das academias.

Portanto, temos que nos perguntar pela crise estrutural, cada vez mais profunda, do sistema capitalista. Temos que reconhecer a necessidade da implantação da alternativa socialista, e isto não será fruto de ponderações teóricas, mas, sim, da crise estrutural, cada vez mais profunda, do sistema do capital global.

Esta crise estrutural determina as reformas do Estado (previdência, sindical, trabalhista, tributaria, do judiciário, da educação e outras) que retiram direitos constitucionais, a reestruturação produtiva do mundo do trabalho, intensificando, precarizado, flexibilizando o trabalho o que gera mentalidades conformadas, vez que a consciência é determinada pela atividade humana (LEONTIEV,1981).

O que temos que reconhecer é onde acumulamos força para transformar a sociedade. $\mathrm{O}$ acesso de todos os seres humanos aos bens culturais que garantam a vida digna é uma possibilidade histórica de essência. Para tanto, temos que desenvolver as condições objetivas sintonizados com os movimentos sociais de resistência, em uma ação altamente responsável e voluntariamente assumida por todos nós. Romper com a propriedade privada dos meios de produção, romper com a lógica da subsunção do trabalho ao capital, romper com políticas sociais focais, compensatórias, de alivio da pobreza, na escola e na comunidade, advindas do Estado burguês e de governos mantidos por conciliações de classes é uma tarefa histórica da classe trabalhadora.

É necessário enfrentar a lógica da organização da escola e da educação, no processo de trabalho pedagógico e nas políticas públicas. As "inovações" pedagógicas e as políticas assistencialistas, focais, compensatórias, por exemplo, a política de cotas para "excluídos", não enfrentarão a gravidade da situação educacional no Brasil. Fora do contexto das lutas mais gerais contra a lógica capitalista imperialista, fora do acúmulo de forças para resistir e transformar, estas medidas serão facilmente barradas e diluídas, cooptadas e amoldadas.

\section{CONCLUSÃO}

A educação e o esporte por si só não tem como enfrentar as contradições de um sistema que determina quem é eliminado ou não, quem é explorado ou não, quem é oprimido ou não, quem é incluído ou excluído da classe burguesa. E isto não ocorre sem as devidas mediações asseguradas por intelectuais e aparelhos ideológicos. O capitalismo vive disto, ele é isto e estamos todos incluídos nesta barbárie, nesta condição pré-histórica de relações sociais de produção. Ou a educação e o esporte se 
sintonizam com a revolução no contexto de resistência e de luta concreta pela transformação no sentido socialista ou continuará discursando sobre a sua capacidade de inclusão que é aparente e só aparente.

As ilusões nas políticas de conciliação de classes estão sendo destruídas. Esta sendo revelada a classe trabalhadora, mais uma vez, agora na situação atual do Brasil, " a oposição hostil entre os seus interesses e os da burguesia (Lênin, 1988, p. 13). É necessário retomar premissas programáticas contra o praticismo estreito (ativismo desvairado), a dispersão e o caráter artesanal do movimento socialista, avançando em uma forma superior, mais unificada e meIhor organizada de luta. E isto passa pela teoria da transição e pelas premissas de um Programa de Transição e não por políticas sociais compensatórias que iludem os trabaIhadores com a falsa idéia da "inclusão social". Um dos estudos atuais que apresenta elementos sobre as ilusões nas políticas de cotas é o trabalho de Figueiredo (2011). A autora demonstra que a democratização do acesso e permanência na Educação Superior dependem de outra política. As "lições da experiência" da UFBA, demonstram o que é a "inclusão excludente" articulada às políticas para conciliação de classe necessárias ao processo de mundialização do capital e da educação, contribuindo, por meio da integração das reivindicações e da educação dos trabalhadores, para a colaboração e não o confronto de classes.

Portanto, é preciso agir na linha das reivindicações transitórias dos trabalhadores, incluídas no Programa de Transição (TROTSKY, 2008), que significa organizar a luta em torno de necessidades vitais para a classe trabalhadora, que servirá de referencia para as mobilizações e organizações dos que lutam não pela inclusão no sistema capitalista, mas, sim, pela superação de tal modelo, pela alternativa socialista. E isto significa confronto de classes e não conciliação de classe.

A educação escolarizada e o esporte democratizado são espaços estratégicos para o desenvolvimento de uma política cultural na perspectiva da emancipação humana e isto significa romper a subsunção do trabalho com o capital. Significa conquistar as reivindicações transitórias.

O desenvolvimento de tal consciência histórica, de luta, de construção de outra subjetividade humana que se objetiva em outras formas de produção da vida, segundo Meszáros (2002, p. 59) significa o enfrentamento com três problemas a saber: 1. a determinação da ação histórica, o agir humano; 2 . a percepção da mudança não como lapso de tempo mas como um movimento de caráter cumulativo; 3 . a oposição consciente entre particularidade e universalidade, como síntese, de modo a explicar historicamente eventos relevantes e seu significado amplo que transcende o imediato.

Portanto, a construção de alternativas significa assegurar a educação pública, laica, de qualidade unitária, nacional, socialmente referenciada para todos. Assegurar o acesso universal e democrático as praticas corporais esportivas. Isto implica na derrubada de todos os obstáculos que hoje afastam os praticantes do acesso a cultura esportiva. Obstáculos estes relacionados ao financiamento, a infraestrutura, a legislação, a gestão e administração, entre outros.

O trabalho pedagógico deve apontar para a elaboração da teoria da transição, a partir da consideração da prática e sua descrição empírica, de um referencial que 
explique esta pratica, na perspectiva da compreensão da sua totalidade, radicalidade e no conjunto e, da elaboração de proposições coletivas, solidárias, superadoras do atual projeto histórico capitalista.

Este é o enfrentamento para o próximo período, se quisermos agir na linha da superação dos elementos que constitui a contradição de fundo que mantém a maioria excluída do acesso aos bens culturais, entre os quais a educação e o esporte. A questão de fundo não é a inclusão, mas sim, a resistência, a ocupação, a produção, a preservação a partir da determinação responsável e voluntária de produtores associados que têm como elemento regulador, nos planejamentos de baixo para cima do sistema de produção e troca, não as leis do mercado, mas fundamentalmente as necessidades vitais do SER HUMANO.

A isto Meszáros (2002) em sua obra "Para além do capital: Rumo a uma teoria da transição" denomina de principais princípios da alternativa socialista. A libertação dos trabalhadores pode vir apenas pelos próprios trabalhadores ressalta Trotsky (2009, p. 92) em seu livro "Modo de Vida". "Participar deste movimento, com os olhos bem abertos e uma intensa vontade, pode dar a mais alta satisfação moral a um ser pensante".

\section{REFERÊNCIAS}

A VERDADE. Revista teórica da $4^{\mathrm{a}}$ Internacional. São Paulo, n.73, jun.2012.

BEER, Max. História do socialismo e das lutas sociais. Tradução Horácio de Melo. São Paulo: Expressão Popular, 2006.

CHAVES, Vera Lúcia Jacob. Crise e privatização da universidade pública: de Fernando Henrique a Lula da Silva. Universidade e Sociedade, Distrito Federal, ano XVI, n.38, p.61-77, jun.2006.

ENGELS, Friedrich. Do socialismo utópico ao socialismo científico. São Paulo: Ed. Moraes, s/d.

FIGUEIREDO; Erika Suruagy Assis de. As ações afirmativas na Educação Superior: Política de Inclusão ou Exclusão? Feira de Santana/BA UEFS, 2011.

FREITAS, Luiz Carlos. A dialética da inclusão e da exclusão: Por que as mudanças não acontecem. II SEMINÁRIO INTERNACIONAL DE EDUCAÇÃO. Anais... Campinas/SP, julho de 2003.

FRIGOTTO, Gaudêncio. Os circuitos da história e o balanço da educação no Brasil na primeira década do século XXI. Revista Brasileira de Educação, Rio de Janeiro, v.16, n.46, p.235-254, jan./abr.2011.

GASPAR, Luis Carlos de Jesus; PICH, Santiago; VAZ, Alexandre Fernandes. Política pública de esporte escolar e educação física escolar: entre a inclusão social e a busca por talentos esportivos, tendo como pano de fundo o Programa Estadual Esporte Escolar de Santa Catarina. Motrivivência, Florianópolis, ano XIV, n.23, p.103-116, dez. 2004.

GENTILI; Pablo. A exclusão e a escola: o apartheid educacional como política de ocultação. In: GENTILI, Pablo; ALENCAR, Chico. Educar na esperança em tempos de desencanto. Petrópolis: Vozes, 2001.

LÊNIN, Vladimir III'ich. O imperialismo, fase superior do capitalismo. Tradução José Eudes Baima Bezerra. Brasília: Nova Palavra, 2007. 
LÊNIN, Vladimir III'ich. Que fazer? São Paulo: HUCITEC, 1988.

LEONTIEV; Alexei. Actividad, conciencia, personalidad. La Habana: Editorial Pueblo y Educación, 1981.

MARX, Karl; ENGELS, Friedrich. Manifesto Comunista. São Paulo: Boitempo, 2007. MARX, Karl; ENGELS, Friedrich; LÊNIN, V. L.; TROTSKY, Leon. O programa da revolução. Brasília: Nova Palavra, 2008. MESZÁROS, István. Para além do capital: rumo a uma teoria da transição. São Paulo: Boitempo e UNICAMP, 2002.

OLIVEIRA, Ramon de. O Banco Mundial e o combate à pobreza. Universidade e Sociedade, Distrito Federal, ano XVI, n.38, p.85-93, jun.2006.
SAVIANI, Dermeval. PDE - Plano de Desenvolvimento da Educação: análise crítica da política do MEC. Campinas: Autores Associados, 2009.

TAFFAREL, Celi; GAMBOA, Silvio; CHAVES, Márcia. Prática pedagógica e produção do Conhecimento na Educação Física, Esporte e Lazer. Maceió: Ed.UFAL, 2003.

TOMMASI, L; WARDW, M. HADDAD, S. O Banco Mundial e as Políticas Educacionais. São Paulo: Cortez; PUCSP; Ação Edicativa. 1996.

TROTSKY, Leon. Questões do modo de vida: a moral deles e a nossa. Tradução Diego Siqueira e Daniel Oliveira. São Paulo: Ed. Instituto José Luís e Rosa Sundermann, 2009.

SOCIAL PROGRAMS OF SPORT AND LEISURE IN THE SCHOOL AND IN THE COMMUNITY: the evidences of the social exclusion and educational in the brazilian society

\begin{abstract}
The text presents contents that it goes through the contradiction "exclusion against inclusion", while considering the current reality of the decomposition of the capitalist model and of the destruction of the productive forces, this determines the access possibility historically to the accumulated goods. Makes of the contradiction among work and capital that it is expressed in the social production and in the deprived appropriation of the cultural goods, among them the own education and the sport. Discusses indicators of the education evaluations and the workers' claims and, a transition program in the perspective of the alternative of historical project for besides the capital.
\end{abstract}

Keywords: Public politics; Social programs; Education and Sport

Recebido em: março/2012 Aprovado em: junho/2012 